U POVODU STOGODIŠNJICE ROĐENJA JEDNOG VELIKANA

NAUČNO-STRUČNI DOPRINOS MIRKA JOVANIĆA

U OBLASTI ZAŠTITE BILJA

\title{
SCIENTIFIC-TECHNICAL CONTRIBUTION IN PLANT PROTECTION BY MIRKO JOVANIĆ
}

\author{
Sreten Stamenković \\ Institut za ratarstvo i povrtarstvo, Novi Sad \\ Email: sretenstamenkovic@sbb.rs
}

\begin{abstract}
Izvod
Daje se prikaz ukupne naučno-stručne aktivnosti i doprinos Mirka Jovanića u razvoju i unapređenju struke zaštite bilja u nas. Posebno se prikazuje problematika koju je obrađivao i ukratko iznose rezultati, koji su i danas, svojom aktuelnošću, prepoznatljivi u našoj poljoprivrednoj praksi.

Neosporno, utvrđivanje kritičnih brojeva štetočina za naše uslove, u odnosu na određene vrste gajenih biljaka, te prognoza jačine pojave i određivanje potrebe i vremena suzbijanja, aktuelni su i danas.
\end{abstract}

Ključne reči: doprinos, Mirko Jovanić, zaštita bilja.

\section{UVOD}

Uporedo sa razvojem i unapređenjem poljoprivredne proizvodnje, čovek je bio suočen sa neophodnošću zaštite gajenih biljaka od štetnih organizama. Istina, u početku je ta zaštita bila na skromnom nivou, srazmerno mogućnostima i saznanjima u toj oblasti. Izvodila se, uglavnom, protiv štetočina i prouzrokovača biljnih bolesti. U prvoj polovini prošloga veka kod nas su sprovođene široke akcije suzbijanja masovnih pojava skakavaca, gubara i dudovca, kao i akcije sprečavanja nastanka i širenja epifitotičnih pojava plamenjače vinove loze i krompira. Jedino su se na taj način mogli preduprediti katastrofalni gubici od štetnih organizama. Nauka i struka, koliko su u to vreme mogućnosti dozvoljavale, doprinosile su rešavanju nastalih problema.

Doprinos pojedinca, pogotovu nakon Drugog svetskog rata, u uslovima nedostatka kadrova i neophodne opreme, bio je od ogromnog značaja. Na sreću, kod nas je takvih pojedinaca $u$ to vreme bilo, pre svega, na području Vojvodine. Jedan od njih, ako ne i lider u tome, svakako je bio Mirko Jovanić, o čemu će detaljnije u ovom prilogu biti reči. 


\section{STANJE U NAUCI I STRUCI POLOVINOM PROŠLOGA VEKA}

Da bi se današnjim, mlađim generacijama stručnjaka zaštite bilja što slikovitije približio ambijent u kojem se radilo sredinom prošloga veka, ne samo u zaštiti bilja već, uopšte, u oblasti poljoprivrede, neminovno je nešto reći o stanju u struci. Generalno, osnovni i najveći problem u to vreme bio je nedostatak kadrova, posebno specijalističkih. Ilustracije radi, u periodu pred Drugi svetski rat u Vojvodini je bilo svega tri (!) stručnjaka za zaštitu bilja. Takođe, treba istaći da su se između dva svetska rata, kadrovi iz te oblasti školovali u inostranstvu, uglavnom u Francuskoj, nešto manje u drugim državama. Iz te generacije kadrova, takozvane francuske škole, kasnije su potekli i naši ugledni naučni radnici i univerzitetski profesori iz fitopatologije i entomologije, koji su presudno uticali na razvoj zaštite bilja u nas. Tako su već krajem pedesetih i početkom šezdesetih godina prošloga veka, uglavnom zaslugom tih kadrova, osnovani Odseci za zaštitu bilja na Poljoprivrednim fakultetima u Beogradu - Zemunu (1959) i Novom Sadu (1960). Time su udareni temelji za razvoj zaštite bilja, kao naučne discipline, na ovim prostorima. Sredinom šezdesetih godina, sa tih visokoškolskih ustanova izlaze prvi kadrovi sa fakultetskim obrazovanjem za tu oblast, odnosno stručnjaci za zaštitu bilja. Već sredinom osamdesetih godina u Vojvodini su radila preko 340 takvih stručnjaka u obrazovanju, nauci, širokoj poljoprivrednoj proizvodnji i u oblastima za proizvodnju i promet pesticida.

\section{Rešavanje problema u struci}

Prvih godina nakon Drugog svetskog rata nimalo nije bilo lako uhvatiti se u koštac i rešavati nagomilane probleme, odnosno odgovarati svakodnevnim izazovima u struci zaštite bilja, gde je još uvek bilo mnogo nepoznanica. Najteže je bilo u periodu od završetka rata, pa do kraja pedesetih, odnosno početka šezdesetih godina, kada nije bilo odgovarajućih kadrova ili ih je bilo nedovoljno.

Upravo $u$ tom periodu dolazi do izražaja entuzijazam jedne generacije stručnjaka, koji su u to vreme, kao agronomi sa opštim obrazovanjem, radili u struci zaštite bilja, stičući znanja na terenu, rešavanjem svakodnevnih praktičnih problema. Neki od njih, u međuvremenu su završavali specijalističke kurseve iz zaštite bilja od po nekoliko meseci na našim fakultetima ili institutima koji su se bavili tom problematikom. Bila je to generacija vrsnih i cenjenih stručnjaka koji su radili u rejonskim poljoprivrednim stanicama, odnosno zavodima. Ponosni i nadahnuti time da su stekli nešto novo i do tada nedovoljno poznato u struci, svoja znanja iz zaštite bilja nesebično su prenosili u praksu, istovremeno obučavajući mlađe kolege agronome. Jedan od predvodnika te generacije, kao što je već napomenuto, bio je poznati stručnjak, Mirko Jovanić (1919-2016), koji je, nažalost, pred kraj desete decenije života, preminuo 2016. godine. Čovek širokih pogleda 
i izvanrednih ljudskih osobina, spreman da podeli znanje sa svakim i pomogne kada je najpotrebnije. O njegovom životnom putu i kretanju u službi, ranije su već saopšteni detaljni podaci (Stamenković, 2017).

\section{Doprinos jednog entuzijaste i zaljubljenika u struku}

Sticajem raznoraznih okolnosti, nakon završetka rata i povratka iz logora u Mađarskoj, kao svršeni srednjoškolac, 1946. godine Jovanić se zaposlio u Pokrajinskom zavodu za poljoprivredna istraživanja u Novom Sadu (sada: Institut za ratarstvo i povrtarstvo), u Odseku za zaštitu bilja, gde je proveo ceo radni vek. Tu je u početku, u radu sa bračnim parom Petrik, Cvijetom i Aleksandrom (dvoje od troje stručnjaka zaštite bilja u Vojvodini u predratnom periodu), sticao i usavršavao svoja znanja iz zaštite bilja, u prvom redu iz primenjene entomologije. Mada su do sada, u par navrata, već saopštavani podaci o njegovom ogromnom doprinosu u struci zaštite bilja kod nas (Čamprag, 1980; Stamenković, 2018), namera je da se ovom prilikom detaljnije prikažu pojedini segmenti iz njegovog rada, odnosno saopšte i neki do sada nedovoljno poznati podaci.

Kao entomolog, pre svega, radio je na rešavanju praktičnih problema $u$ struci. Međutim, nije zanemarivao ni naučno-istraživački rad. Bavio se izučavanjem biologije, ekologije, metoda prognoziranja pojave i integralnih mera suzbijanja ekonomski značajnih štetočina u ratarstvu (pšenice, kukuruza, šećerne repe, suncokreta i lucerke). Znači, veoma širok spektar problema u zaštiti bilja. Poput pedantnog i predanog istraživača, sa svojim saradnicima izvodio je brojne oglede u laboratoriji i poljskim (proizvodnim) uslovima.

U laboratojskim uslovima, mada se tada raspolagalo skromnom opremom, koristio je poznate metode za determinaciju i proučavanje bioekologije insekata, sa neophodnom opremom (solidne mikroskope, insektarijume i kaveze za uzgoj insekata, sitnu laboratorijsku opremu, termostate, frižidere), čime su u to vreme raspolagale samo poznatije ustanove. Revnosno je pratio literaturu iz svoje oblasti i uz njegovo zalaganje oformljena je skromna biblioteka u tadašnjem Zavodu za zaštitu bilja, koja je, pored domaće literature, u to vreme sadžavala i najpoznatija dela svetskih entomologa.

U poljskim ili proizvodnim uslovima, kod izvođenja mikro- ili makro ogleda, osnovno načelo je bilo izbor lokacije, pravilno odabrana metodologija rada i korektna i nepristrasna interpretacija dobijenih rezultata. Kod izbora lokacije presudno je bilo da na odabranim parcelama bude insekata iznad kritičnog broja, u odnosu na cilj izvođenja ogleda, bilo da su to bioekološka ispituvanja ili suzbijanje. Pored pravilno odabrane ili postavljene metodologije, bitna činjenica je da je sa saradnicima i neposredno, svojim radom, učestvovao u izvođenju, odnosno postavljanju i ocenjivanju efekata ogleda. Nije se libio da se prihvati trake za razmeravanje ogleda, prskalice, motike ili grabulja. Zbog korektnog izvođenja 
ogleda i nepristrasnog tumačenja dobijenih rezultata, nije neskromno istaći da $\mathrm{su}, \mathrm{u}$ to vreme, mnoge poznate domaće i strane hemijske firme za proizvodnju i promet pesticida na prostorima bivše Jugoslavije, nastojale da poljska ispitivanja efikasnosti svojih proizvoda (preparata) povere ustanovi gde je on radio. Prilikom saopštavanja rezultata na naučno-stručnim skupovima ili seminarima vladalo je ogromno interesovanja, kako ljudi iz obrazovno-naučnih ustanova, tako i iz neposredne proizvodnje, jer je, pre svega, bio veoma iskusan praktičar. Bio je redovan učesnik naučno-stručnih skupova i rado viđen kao predavač (Slika 1).

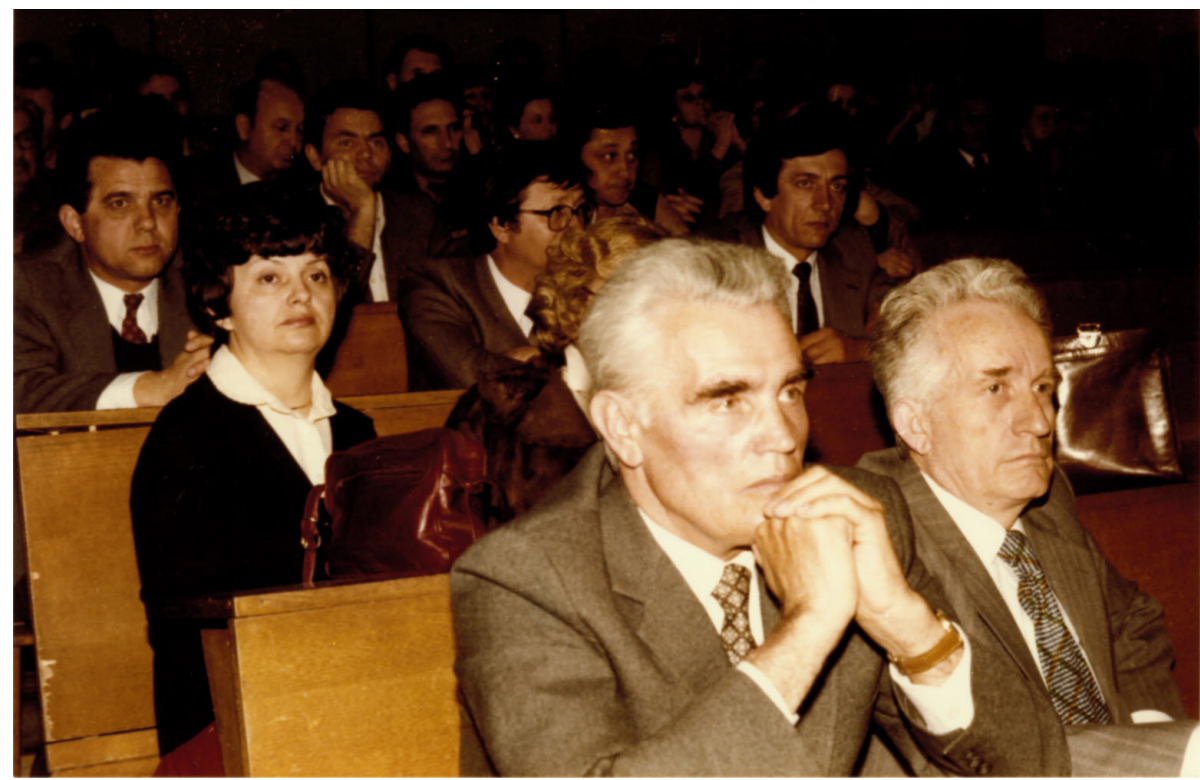

Slika 1. Učešće u radu Seminara iz zaštite bilja, u društvu sa B. Jovićevićem (Novi Sad, 1983)

Njegov doprinos u rešavanju praktičnih problema u neposrednoj proizvodnji bio je od ogromnog značaja i veoma cenjen u struci. Rezultate svojih istraživanja saopštavao je na domaćim i međunarodnim skupovima i objavljivao u domaćim i inostranim časopisima.

\section{Problematika koju je obrađivao}

Krug interesovanja Mirka Jovanića bio je veoma širok. Međutim, posebnu pažnju poklanjao je izučavanju ekonomski najznačajnijih vrsta u Vojvodini, sa naglaskom na suzbijanje. Ukratko će se samo spomenuti problematika koju je tokom svog radnog veka obrađivao.

Za početak rada, svakako, treba istaći najčešće vrste sovica u nas (Noctuidae), koje su bile predmet njegovog interesovanja, naročito krajem četrdesetih 
i početkom pedesetih godina. Brojnost i štetnost gusenica tih štetočina bile su veoma visoke (Petrik, Jovanić, 1952; Jovanić, 1953). Težište je bilo izučavanje biologije i suzbijanje, a sa istraživanjima nije prekidao ni kasnije, kada je to nalagala situacija (Stamenković, Jovanić, 1975).

Značajan problem u to vreme predstavljao je i žitni bauljar (Zabrus tenebrioides) (Petrik, 1951). Zapravo, larve ove štetočine, s vremena na vreme, pričinjavale su značajne štete i kasnije, naročito sa uzgojem strnih žita u ponovljenoj setvi (monokulturi), tako da je bilo neophodno kontinurano praćenje. Naročitu pažnju poklanjao je razradi metoda suzbijanja (Petrik, C., Jovanić, 1964), posebno preventivnom suzbijanju imaga, pre setve pšenice, na površinama gde se planira ponovljena setva (Stamenković, 1984).

Posebno poglavlje u njegovom istraživačkom radu predstavljaju žitne stenice (Eurygaster spp.). Prvi je kod nas ukazao na problem tih insekata (Jovanić, 1959), koji su sredinom šezdesetih godina postali glavne štetočine pšenice (Jovanić, 1965, 1972). Posebno je radio na utvrđivanju kritičnih brojeva za suzbijanje tokom vegetacije pšenice (za imaginalni stadijum i larvalne uzraste - III, IV i V uzrast), kao i predviđanju jačine napada i prognozi pojave u narednoj godini (Jovanić, 1969, 1975; Jovanić, Stamenković, 1978a).

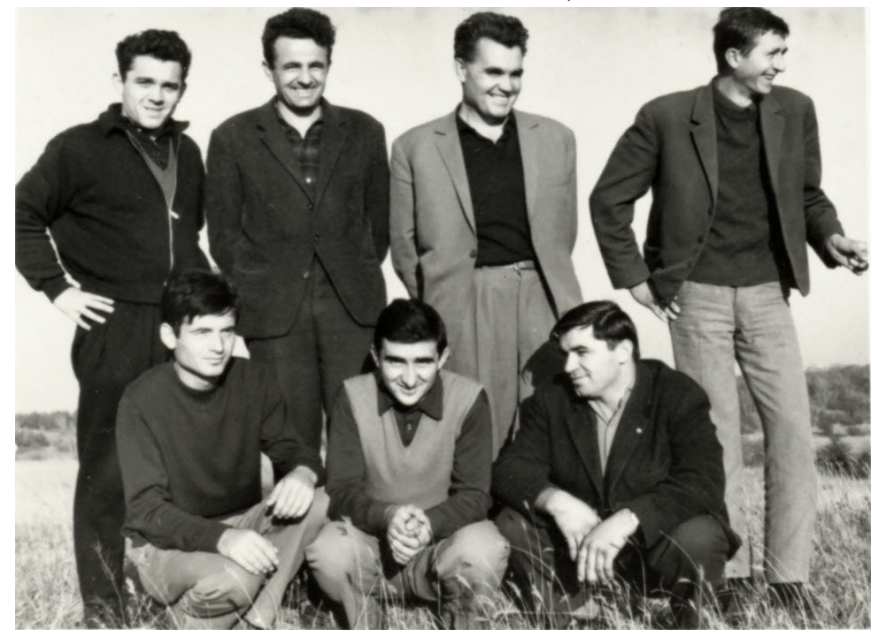

S1. 2. Na terenu sa grupom studenata IV godine smera zaštite bilja

(M. Jovanić drugi s desna, gore) Utvrđivanje brojnosti imaga žitnih stenica na lokalitetu Deliblatske peščare (oktobra 1965)

U cilju prognoze pojave u narednoj godini, za naše uslove razradio je metode utvrđivanja brojnosti imaga na mestima prezimljavanja. Svake godine, u jesen i proleće, uzimani su uzorci na odabranim lokalitetima Deliblatske peščare i Fruške gore, a povremeno i Vršačkog brega (Slika 2). Sredinom šezdesetih godina, kada je brojnost ovih štetočina bila veoma izražena, pod njegovim nadzorom 
obavljano je i avio-suzbijanje na više desetina hiljada hektara pod pšenicom u Vojvodini (Balarin, I., Jovanić, 1965).

Poznato je da su kod nas larve skočibuba - žičari (Elateridae) problem, koji se javlja svake godine, posebno na površinama pod okopavinama. Naročito se zalagao pravilnom pristupu u suzbijanju (Stamenković, Jovanić, 1972, 1973). U cilju ustanovljavanaja brojnosti, prognozi pojave i potrebi suzbijanja, u jesen svake godine uzorkovane su površine predviđene za setvu okopavinskih useva narednog proleća. Posebno je ukazivao na značaj kritičnih brojeva po jedinici površine za pojedine gajene biljke. Tamo gde je bila povećana brojnost preporučivane su mere zaštite istovremeno sa setvom. Međutim, tamo gde je bila znatno iznad kritične za određeni usev, preporučivana je setva druge, tolerantnije biljne vrste, naravno, uz odgovarajuće mere zaštite.

Jedan od značajnih problema u nas, koji je zaokupljao pažnju ovog istraživača, svakako, bio je i kukuruzni plamenac (Pyrausta=Ostrinia nubilalis). U godinama masovne pojave, na terenu je utvrđivan broj napadnutih biljaka gusenicama ovog insekta, odnosno stepen zaraze, a na osnovu toga određivana potreba suzbijanja i momenat izvođenja zaštitnih mera. Zalagao se za masovniju primenu biopreparata, posebno u kukuruzu šećercu (Jovanić, 1974; Jovanić, Stamenković, 1978b).

Pored navedenog, predmet njegovog interesovanja, naročito sa stanovišta suzbijanja, bile su i najvažnije vrste pipa na šećernoj repi, lucerki, kukuruzu i suncokretu (Curculionidae), zatim mušica lucerkinog cvetnog pupoljka i lucerkine mahune (Cecidomyiidae). Takođe, vrste koje su se u nas pojavljivale povremeno u značajnijoj meri, kao što su konopljin savijač (Grapholitha sinana = Cydia delineana), metlica (Loxostege sticticalis), lisni miner na pšenici (Domomyza ambigua) (Jovanić, Stamenković, 1976; Stamenković, Jovanić, 1974) i druge.

Ogroman stručni doprinos ogledao se i u radu na obrazovanju stručnjaka i saradnji sa poljoprivrednim ustanovama, u prvom redu sa rejonskim stanicama za zaštitu bilja i poljoprivrednim stanicama, a potom i velikim sistemima u to vreme (poljoprivrednim dobrima i kombinatima). U poljoprivrednu praksu prenosio je rezultate višegodišnjih istraživanja i bogata sopstvena iskustva, čime je dao neprocenjivi doprinos unapređenju struke zaštite bilja. Uvođenjem metoda prognoziranja pojave pojedinih štetočina, što je usput već pominjano (žičara, sovica, žitnih stenica, žitnog bauljara, kukuruznog plamenca i dr.), dao je značajan doprinos racionalnoj i ekonomičnijoj primeni pesticida, odnosno zaštiti životne sredine. 


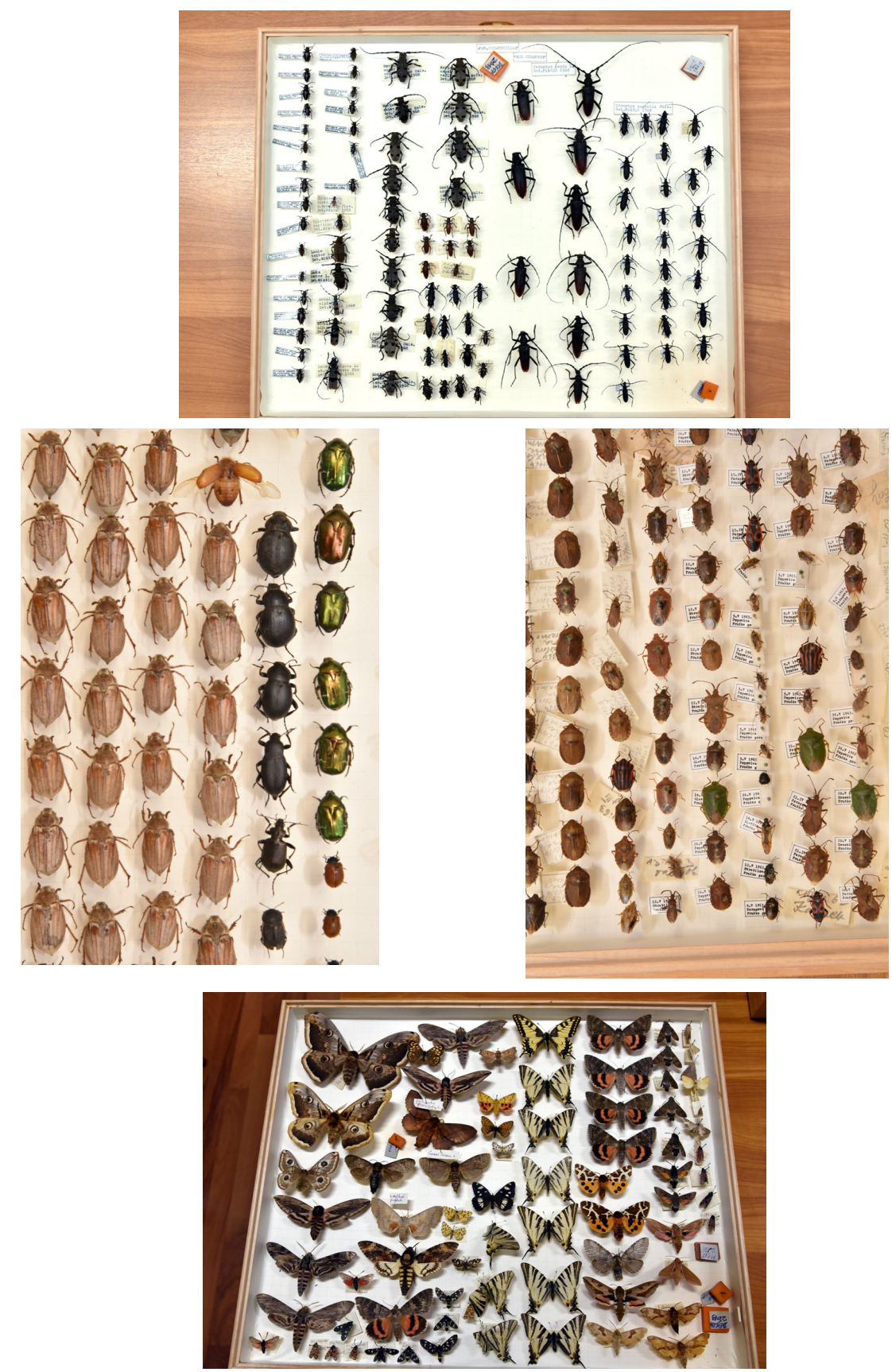

Slika 3. Deo materijala iz bogate insekatske zbirke M. Jovanića (Foto: G. Mulić) 
Naročito je od velikog značaja bilo utvrđivanje kritičnih brojeva za pojedine štetočine i određivanje momenta suzbijanja na određenim gajenim biljkama. Zahvaljujući tome, suzbijanje štetočina je izvođeno samo na delu površina, odnosno delovima parcela gde je to bilo potrebno, čime su ostvarivane ogromne materijalne uštede. Sa današnje vremenske distance, kada se to pokušava uraditi putem satelitskog osmatranja, zvuči prosto neverovatno - kao preteča nečega što će se događati kroz nekoliko decenija. Sumirajući sve napred rečeno, bez preterivanja se može reći da je prvi kod nas u praksu uveo racionalnu primenu insekticida u suzbijanju žičara, kukuruznog plamenca, žitnog bauljara i žitnih stenica. Izuzetno se zalagao za uvođenje bioloških preparata u suzbijanju gusenica kukuruznog plamenca, lisnih sovica i dudovca.

Kao poznati i priznati naučnik i stručnjak, 1978. godine izabran je za prvog predsednika Društva za zaštitu bilja Vojvodine, u okviru Saveza društava za zaštitu bilja Jugoslavije. Za doprinos u razvoju i unapređenju struke zaštite bilja, 1981. godine uručena mu je Povelja Saveza društava za zaštitu bilja Jugoslavije.

\section{Proučavanje entomofaune Fruške gore}

Pored svih svojih redovnih aktivnosti, kao entuzijasta i zaljubljenik u prirodu i entomologiju, najviše u slobodnom vremenu, bavio se i izučavanjem entomofaune Fruške gore. Tokom višegodišnjeg rada oformio je veliku zbirku insekata od neprocenjive vrednosti, koja sadrži na desetine hiljada primeraka (Slika 3).

Zbirku je, kao svoj legat, poklonio Departmanu za fitomedicinu i zaštitu životne sredine Poljoprivrednog fakulteta u Novom Sadu, gde se i sada čuva. Veoma korisno za buduće generacije bilo bi da se zbirka faunistički obradi i kao takva sačuva od propasti i zaborava.

\section{UMESTO ZAKLJUČKA}

Sve ovo učinilo je da je Mirko Jovanić bio veoma cenjen u agronomskoj struci, naročito u oblasti zaštite bilja, kako u stručnim, tako i naučnim krugovima. Bio je omiljen i rado viđen u svakoj sredini, posebno na terenu, gde je najviše vremena provodio u polju, sa svojim kolegama - zaštitarima. Njegova reč se sa pažnjom slušala, naročito preporuke za široku praksu. Za rešavanje brojnih problema u suzbijanju štetočina u ratarskoj proizvodnji, uvek je traženo njegovo mišljenje.

Stoga, nije neskromno reći da je i sa današnje tačke gledišta, njegov doprinos razvoju i unapređenju struke zaštite bilja u nas, sredinom prošloga veka, bio od ogromnog značaja. 
Neka bude dopušteno autoru ovog priloga da iznese neke lične impresije. Imao sam privilegiju da sa Jovanić Mirkom radim punih 15 godina u Institutu za ratarstvo i povrtarsvo u Novom Sadu, od početka sedamdesetih do sredine osamdesetih, sve do njegovog odlaska u penziju. Od toga, kao najbliži saradnici, sedam godina radili smo u Zavodu za zaštitu bilja. Ranih sedamdesetih, kao asistent - entomolog počeo sam upravo kod Mirka. Bila je izuzetna čast raditi sa takvim čovekom. On mi je predložio i temu za doktorski rad - proučavanje žitnih stenica. Njegovi saveti i bogato iskustvo u toj oblasti bili su mi dragoceni.

\section{LITERATURA}

Balarin, Inoslava, Jovanić, M. (1965): Poznavanje i suzbijanje žitnih stenica. Dokumentacija za tehnologiju i tehniku u poljoprivredi, Beograd, sv. 7/65, separat 113, 1-11.

Čamprag, D. (1980): Doprinos Mirka Jovanića unapređenju zaštite bilja u Vojvodini (povodom 60 godina života). Prvo jugoslovensko savetovanje o primeni pesticida u zaštiti bilja (Kupari, 19-23.XI 1979). Zbornik radova, sv. 1, Beograd, 589-591.

Jovanić, M. (1953): Prilog poznavanju biologije proletnje sovice u Vojvodini i ogledi za njeno suzbijanje. Zaštita bilja, Beograd, 20, 47-70.

Jovanić, M. (1959): Žitne stenice na pšenici. Savremena poljoprivreda, Novi Sad, VII, 11, 921-927.

Jovanić, M. (1965): Problem žitnih stenica sa osvrtom na njihovu štetnost kod nas. Savremena poljoprivreda, Novi Sad, XIII, 2, 157-166.

Jovanić, M. (1969): Predviđanje jačine napada žitnih stenica u Vojvodini 1969.godine. Biljni lekar, Beograd, XIV, 1, 5-8.

Jovanić, M. (1972): Prilog proučavanju žitnih stenica sa posebnim osvrtaom na Eurygaster vrste. Zbornik radova Instituta za poljoprivredna istraživanja, Novi Sad, VIII, sv. 8, 129-156.

Jovanić, M. (1974): Ispitivanje efikasnosti preparata Dipel granulat, (Bacillus thuringiensis), za suzbijanje kukuruznog plamenca. Godišnji izveštaj Instituta za poljoprivredna istraživanja, Novi Sad.

Jovanić, M. (1975): Mogućnosti predviđanja jačine pojave žitnih stenica u Vojvodini. Žito-hleb, Novi Sad, II, 1, 30-32.

Jovanić, M., Stamenković, S. (1976): Pojava i suzbijanje metlice u Vojvodini 1975. godine. Savremena poljoprivreda, Novi Sad, XXIV, 1-2, 75-90.

Jovanić, M., Stamenković, S. (1978a): Prognose des Getreide wanzenauftretens (Eurygaster austriaca und E. maura) im nordöstlichen Jugoslawien. Schaderreger in der Industriemässigen Getreideproduktion, Kongress und Tagungsberichte der Martin-Luther-Universität Halle-Witenberg Wissenschaftliche Beiträge, Halle, 1978/14 (S 11), 173-178.

Jovanić, M., Stamenković, S. (1978b): Mogućnost suzbijanja nekih vrsta insekata bakterijskim preparatom "Dipel”. Zbornik radova saopštenih na VIII Savetovanju o primeni pesticida u zaštiti bilja, higijeni i u veterini (Poreč, 1977), 131-136. 
Petrik, A. (1951): Žitni baualjar i njegovo suzbijanje, str. 1-36. Zadaružna knjiga, Beograd. Petrik, A., Jovanić, M. (1952): Prilog poznavanju najčešćih sovica (Noctuidae) Vojvodine. Zbornik Matice srpske, sv. 3, Novi Sad.

Petrik, Cvijeta, Jovanić, M. (1964): Sadašnje stanje žitnog bauljara u Jugoslaviji i metode za njegovo rešavanje. Savremena poljoiprivreda, Novi Sad, XII, 11, 853-859.

Stamenković, S. (1984): Preventivno suzbijanje umaga žitnog bauljara. Glasnik zaštite bilja, Zagreb, VII, 11, 390-393.

Stamenković, S. (2017): In Memoriam - Mirko Jovanić (1919-2016). Biljni lekar, Novi Sad, 45, 3, 362-363.

Stamenković, S. (2018): Veliki stručnjak Mirko Jovanić - Značajan doprinos razvoju i unapređenju struke zaštite bilja. Poljoprivrednikov poljoprivredni kalendar 2018. Dnevnik-Poljoprivrednik AD, Novi Sad, 108-109.

Stamenković, S., Jovanić, M. (1972): Prilog metodici i problematika suzbijanja žičara. Agronomski glasnik, Zagreb, 11-12, 671-682.

Stamenković, S., Jovanić, M. (1973): Suzbijanje žičara (Elateridae) u uslovima Vojvodine. Savremena poljoprivreda, Novi Sad, XXI, 7-8, 55-70.

Stamenković, S., Jovanić, M. (1974): Lisni miner (Domomyza ambigua Fall.) na pšenici. Savremena poljoprivreda, Novi Sad, XXII, 1-2, 101-106.

Stamenković, S., Jovanić, M. (1975): Suzbijanje gusenica ozimih sovica (Agrotis sp.). Savremena poljoprivreda, Novi Sad, XXIII, 7-8, 71-80. 